\title{
Lo que nos chirría en la Educación Infantil
}

\section{What would squeak us in Early Childhood Education}

\author{
Mari Carmen Díez Navarro ${ }^{1}$
}

Recibido: 21 de noviembre de 2019 Aceptado: 17 de diciembre 2019 Publicado: 31 de enero de 2020

To cite this article: Díez Navarro, $M^{\mathrm{a}}$ C. (2020). Lo que nos chirría en la Educación Infantil. Márgenes, Revista de Educación de la Universidad de Málaga, 1 (1), 232-236

Dol: http://dx.doi.org/10.24310/mgnmar.v1i1.7210

\section{${ }^{1}$ Mari Carmen Díez Navarro \\ Maestra de Educación Infantil y psicopedagoga \\ http://carmendiez.com}

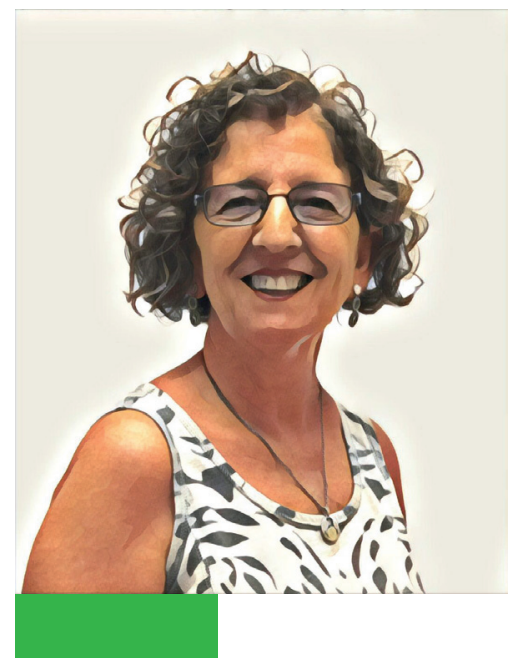

\section{RESUMEN}

Es a partir de la duda, la insatisfacción o la falta desde donde nos animaremos a probar algo diferente. Es a partir de sentir que no estamos contentos con determinada práctica, actitud o criterio, desde donde nos movilizaremos para procurar mejorar. Por eso hay que incorporar el mirar de vez en cuando lo que no tenemos claro. Eso indica que no hay anquilosamiento, pasividad, ni apatía, sino permeabilidad, apertura, deseo y disposición a buscar nuevas sendas. 0 sea, señas de vida, de avance, de movimiento, de latido.

Palabras clave: práctica reflexiva; indagación; mirada; escucha; educación infantil

\begin{abstract}
It's from the doubt, dissatisfaction or lack from where we will be encouraged to try something different. It's from feeling that we are not happy with certain practice, attitude or criteria, from where we will mobilize to try toimprove. That's why we need look again, from time to time, which is not clear to us. That indicates that there is no ankylosing, passivity or apathy; but, permeability, openness, desire and willingness to seek new paths. That is, signs of life, of progress, of movement, of heartbeat.
\end{abstract}

Keywords: reflective practice; inquiry; look; listening; early childhood education

Cuando miramos de cerca la realidad de nuestras escuelas infantiles y escuchamos las dudas, quejas y alegrías que cuentan las maestras y maestros que las habitan, nos aparece una cotidianidad llena de acon- 


\section{H I S T O R I A S M Í N I M A S}

tecimientos, de sorpresas, de aprendizajes y de buenos encuentros. Aunque también emergen algunas cosas que nos chirrían, que no nos satisfacen o que nos plantean dudas. Aquellos agujeros no del todo resueltos, aquellos problemas nuevos en los que no sabemos cómo intervenir, aquellos aspectos que no hemos revisado hace años como si fueran de validez eterna, aquellos criterios que se nos han colado a partir de las modas pedagógicas, de las costumbres o manías de los centros o nuestras, de los materiales que disfrazan las rutinas de novedades a todo color...

Es decir, aquellas prácticas de dudosa utilidad, que en su día a lo mejor cumplieron su papel, pero que ahora, aunque ya no nos convencen, nos resistimos a cambiar o suprimir de nuestro día a día. Quizás por miedo a abandonar lo conocido, que nos da seguridad. Quizás por no atrevernos a buscar alternativas coherentes con lo que deseamos mejorar. Quizás por miedo ante esos cambios soñados, pero que tienen el riesgo de fracasar, de no responder a nuestras expectativas, o de ser criticados por nuestro entorno.

Sin embargo, es a partir de las carencias desde donde nos sentiremos impulsados a buscar algo nuevo. Es a partir de la duda, la insatisfacción o la falta desde donde nos animaremos a probar algo diferente. Es a

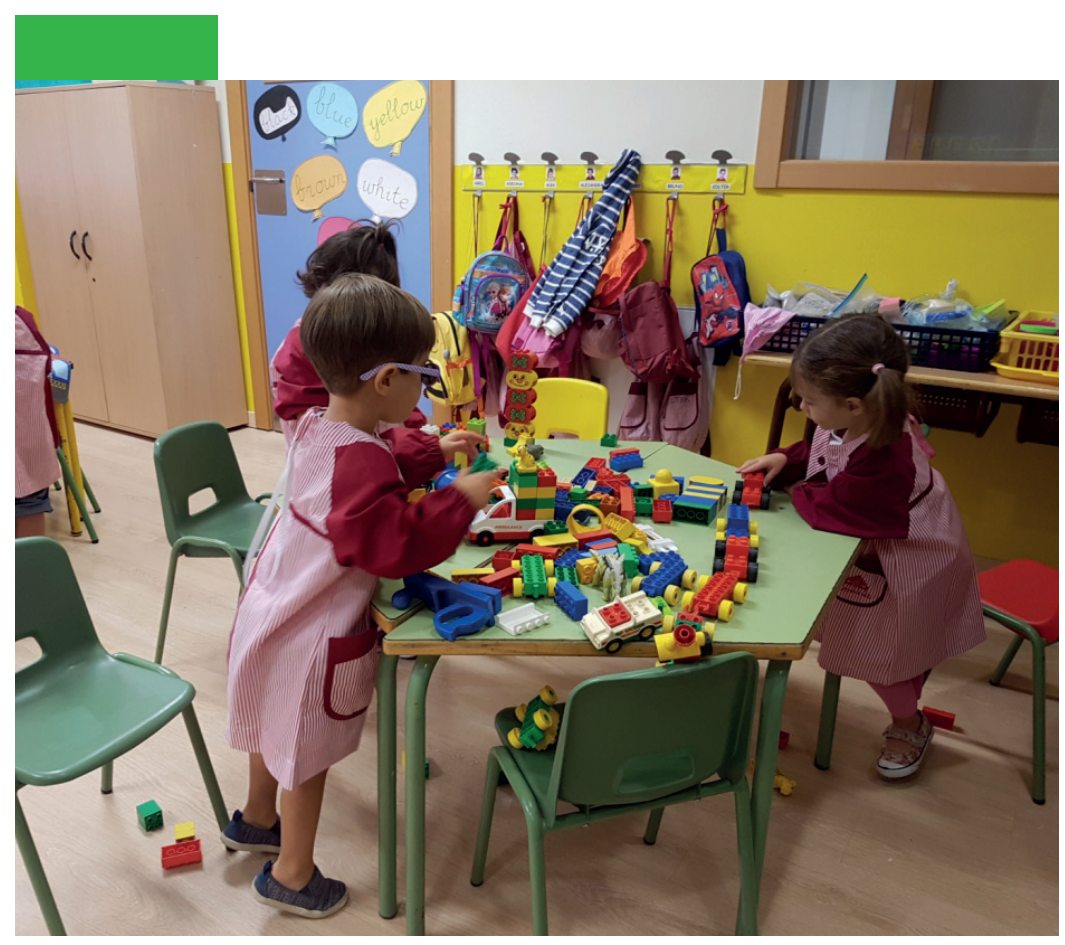

4 Es a partir de sentir que no estamos contentos con determinada práctica, actitud o criterio, desde donde nos movilizaremos para procurar mejorar. 


\section{H I S T O R I A S M Í N M A S}

\section{Aquellas prácticas de dudosa utilidad, que en su día a lo mejor cumplieron su papel, pero que ahora, aunque ya no nos convencen, nos resistimos a cambiar o suprimir de nuestro día a día.}

partir de sentir que no estamos contentos con determinada práctica, actitud o criterio, desde donde nos movilizaremos para procurar mejorar. Por eso hay que incorporar el mirar de vez en cuando lo que no tenemos claro. Eso indica que no hay anquilosamiento, pasividad, ni apatía, sino permeabilidad, apertura, deseo y disposición a buscar nuevas sendas. 0 sea, señas de vida, de avance, de movimiento, de latido.

Hace unos años mis compañeros y yo nos lamentábamos al notar que los intereses de los niños iban en una dirección y nuestras propuestas en otra. Recuerdo que una vez los niños perseguían escarabajos entusiasmadamente por el patio, pero al entrar a clase hablábamos de "los medios de transporte", que era el tema que tocaba en la planificación de centros de interés que teníamos hecha. Y ni nos atrevíamos a decantarnos por seguir los deseos de los niños, ni trabajábamos con satisfacción lo que teníamos previsto. Total, que se produjo un gran chirrido que nos sirvió para ponernos en marcha. Nuestro descontento nos hizo buscar otras maneras, así que de los centros de interés, cerrados y planificados, pasamos primero a recoger de los juegos de los niños las temáticas que más les llamaban la atención, y después a darles a elegir sobre qué temas querían aprender. Y entonces fue cuando empezaron a surgir con gran fuerza nuestros primeros proyectos de trabajo.

También pasó algo así con la lectura. En mi escuela seguíamos el método global, adaptando a Freire, aunque en vez de partir de una frase significativa, partíamos de una palabra generadora, que primero leíamos, escribíamos, comentábamos y reconocíamos, y después descomponíamos en sílabas, llegando al final a las letras. En este proceso estábamos cuando vi a Pablo totalmente absorto delante de los carteles de los nombres de los niños de la clase. Parecía que "murmuraba" alguna cosa. Le pregunté qué estaba haciendo y me dijo que "aprender a leer”. “¿Y cómo lo haces?”. "Pues me fijo bien y me los voy aprendiendo. Ahora sólo me quedan los largos: Valentina, José Manuel y Lorenzo". Le dije por qué no aprendía en las palabras que estábamos trabajando todos (PAPÁ, MAMÁ, LOLA, IBI, NENE), y me contestó que eran muy fáciles. Y ahí fue cuando 
noté otro chirrido, porque supe que tenía razón en lo que me señalaba. Había más de una vía de aprendizaje.

Así que me vi en la tesitura (y en el vértigo) de abrir la mano y permitir, e incluso promover, que en mi clase convivieran varias maneras de aprender a leer, que cada cual iba tomando según su grado de madurez, sus aptitudes y su estilo personal. Esto me obligó a repasar libros, a hablar con los compañeros, a probar, a revisar, a asustarme, a dudar y a aprender.

Me ocurrió de modo similar con las producciones plásticas, con los talleres, con el arte, con los agrupamientos mixtos, con el tratamiento de lo emocional... 0 sea, que en mi experiencia profesional, cuando algo me chirriaba por dentro, primero hacía por resistirme, pero luego, al no poder ignorar por más tiempo mi carencia, iniciaba los pasos para cambiar. Así al menos me ha venido ocurriendo a mi, no sé cómo serán los procesos de otros. Y es que creo que conviene escuchar cuando nos chirría algo. Conviene no perder de vista lo que pensamos que necesita un niño, lo que siente, el modo en el que aprende.

Y si creemos de verdad que el niño ha de ir caminando hacia su autonomía, tendremos que pararnos a pensar en las muchas ocasiones en que se puede empezar a ejercer en nuestras clases. ¿Aprender así o asá? ¿Elegir sitios o asignarlos? ¿Elegir actividades o darles todo pautado? ¿Elegir temas o seguir una programación prefijada? Esto no quiere decir que el adulto se borre y abandone su papel de acompañante y guía, pero sí que indica un buen grado de confianza y una valoración a las ideas y las propuestas de los niños.

Si creemos que el niño ha de ser escuchado y ha de poder hablar, nos plantearemos el papel de las conversaciones con los niños. Y pensaremos si convienen las asambleas fijas, las ocasionales, las que tratan temas puntuales o conflictos, las que se hacen por las mañanas tipo "rutinas", las que son más flexibles.

Si creemos que el niño ha de alfabetizarse emocionalmente, buscaremos qué lugar dar al "piso de abajo", y cómo tratar los temas afectivos.

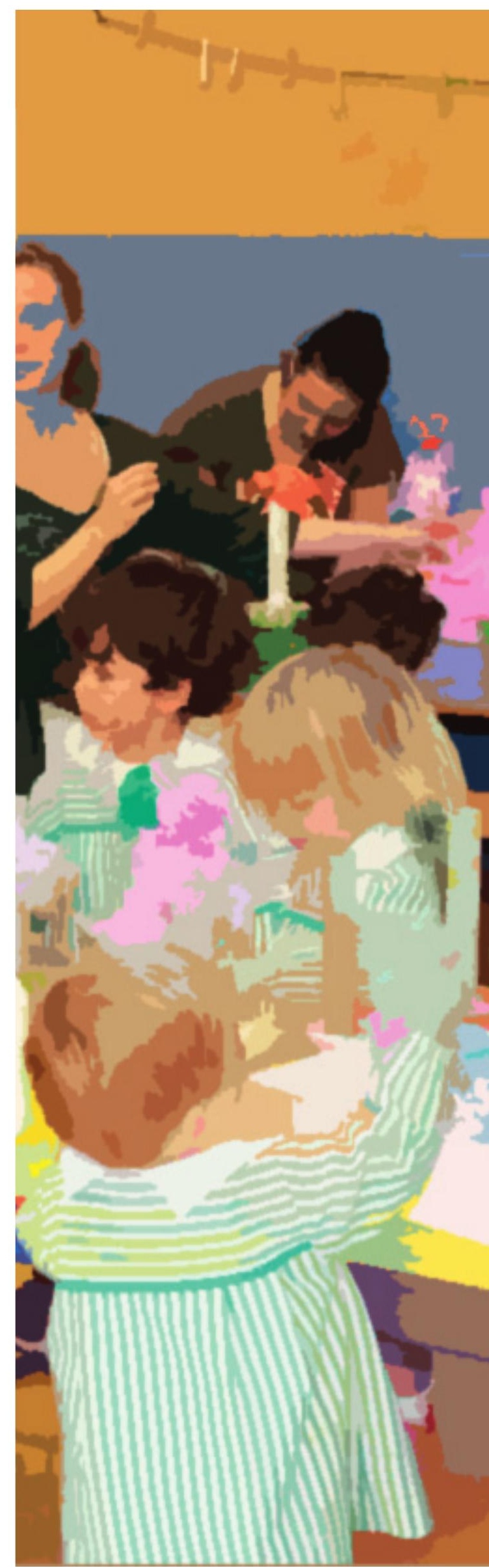




\section{H I S T O R I A S M Í N I M A S}

46 Creo que conviene escuchar cuando nos chirría algo. Conviene no perder de vista lo que pensamos que necesita un niño, lo que siente, el modo en el que aprende.
Si creemos que es importante construir la identidad, pero también vivir incluido en el grupo..., decidiremos cómo intervenir para favorecer tanto lo de cada uno, como lo del grupo.

Si creemos que el niño ha de aprender "en movimiento" reflexionaremos sobre cómo y cuándo dar lugar a que los niños se muevan a lo largo del día. ¿En psicomotricidad, en el patio, en algún otro momento?

Si creemos que para el niño es importante jugar, pensaremos en qué momentos les facilitaremos el juego. Y si será libre o dirigido, con materiales didácticos y estructurados o de desecho...

Si creemos que el niño ha de acercarse a la belleza y caminar hacia la creatividad, tendremos que razonar acerca de cómo organizaremos la estética de los espacios de la escuela, cómo trabajaremos el arte, la música, el cuento, la poesía y el teatro.

Si creemos que el niño ha de estimar las palabras, las letras, los libros... buscaremos el modo de llevarles de la mano hasta la lectura y la escritura.

Si creemos que las familias han de formar parte del entramado educativo también en la escuela, buscaremos las estrategias más adecuadas para lograrlo. Y así.

Así que desde este pequeño escrito propongo hacer caso a lo que nos sugiere mi querida amiga Beatriz Trueba: "Del mismo modo que al pez de las profundidades le desaparecen los ojos porque no los necesita, podríamos preguntarnos cuánto hay en nuestras escuelas que debería desaparecer por innecesario, por inútil, por carente de sentido... Miremos con ojos críticos, con ojos de niño a nuestro alrededor, activemos la escucha y desechemos lo que no responde a ninguna necesidad real, sino a rutinas inertes. Así, del mismo modo que avanza la evolución y la vida al crear nuevas formas, nuestras escuelas irán avanzando en consonancia con el avance de los tiempos, de la inteligencia y de los anhelos profundos de pequeños y adultos". 